\title{
Serial interferon-gamma release assays during treatment of active tuberculosis in young adults
}

Sei Won Lee ${ }^{1,2}$, Choon-Taek Lee ${ }^{2}$ Jae-Joon Yim ${ }^{3^{*}}$

\begin{abstract}
Background: The role of interferon- $\gamma$ release assay (IGRA) in monitoring responses to anti-tuberculosis (TB) treatment is not clear. We evaluated the results of the QuantiFERON-TB Gold In-tube (QFT-GIT) assay over time during the anti-TB treatment of adults with no underlying disease.

Methods: We enrolled soldiers who were newly diagnosed with active TB and admitted to the central referral military hospital in South Korea between May 1, 2008 and September 30, 2009. For each participant, we preformed QFT-GIT assay before treatment (baseline) and at 1, 3, and 6 months after initiating anti-TB medication.

Results: Of 67 eligible patients, 59 (88.1\%) completed the study protocol. All participants were males who were human immunodeficiency virus (HIV)-negative and had no chronic diseases. Their median age was 21 years (range, 20-48). Initially, 57 (96.6\%) patients had positive QFT-GIT results, and 53 (89.8\%), 42 (71.2\%), and 39 (66.1\%) had positive QFT-GIT results at 1, 3, and 6 months, respectively. The IFN- $\gamma$ level at baseline was $5.31 \pm 5.34 \mathrm{IU} / \mathrm{ml}$, and the levels at 1, 3, and 6 months were $3.95 \pm 4.30,1.82 \pm 2.14$, and $1.50 \pm 2.12 \mathrm{IU} / \mathrm{ml}$, respectively. All patients had clinical and radiologic improvements after treatment and were cured. A lower IFN- $\gamma$ level, C-reactive protein $\geq 3$ $\mathrm{mg} / \mathrm{dl}$, and the presence of fever $\left(\geq 38.3^{\circ} \mathrm{C}\right)$ at diagnosis were associated with negative reversion of the QFT-GIT assay.

Conclusion: Although the IFN- $\gamma$ level measured by QFT-GIT assay decreased after successful anti-TB treatment in most participants, less than half of them exhibited QFT-GIT reversion. Thus, the reversion to negativity of the QFTGIT assay may not be a good surrogate for treatment response in otherwise healthy young patients with TB.
\end{abstract}

\section{Background}

Tuberculosis (TB) remains one of the most significant infectious diseases worldwide. Despite intensive global efforts, the number of new TB cases continues to increase, with 9.27 million new cases and 1.78 million deaths in 2006 [1]. Rapid diagnosis and appropriate treatment of $\mathrm{TB}$ are important not only for the health of individuals but also for effective disease control in a population. To evaluate treatment efficacy, sputum microscopy is still used, despite its reportedly low sensitivity [2].

The interferon-gamma release assay (IGRA) has recently been adopted for detecting TB infection [3]. Its role in the diagnosis of latent TB infection (LTBI) is

\footnotetext{
* Correspondence: yimij@snu.ac.kr

${ }^{3}$ Division of Pulmonary and Critical Care Medicine, Department of Internal Medicine and Lung Institute, Seoul National University College of Medicine, Seoul, Republic of Korea

Full list of author information is available at the end of the article
}

promising [4], and it has some advantages over the tuberculin skin test (TST): it is not affected by previous Bacille Calmette-Guérin (BCG) vaccination, it minimizes technical errors, and it has higher specificity [5]. However, its application in assessing treatment efficacy is not clear [6]. Several reports have suggested that the IGRA is useful for evaluating the efficacy of treatment for active TB, although most of the studies enrolled a small number of patients or those with various immune statuses [7-10].

To examine the potential of the IGRA as a surrogate for treatment response among young immunocompetent patients with $\mathrm{TB}$, we evaluated the sequential changes in the interferon-gamma (IFN- $\gamma$ ) level measured by the QuantiFERON-TB Gold In-tube (QFT-GIT; Cellestis, Victoria, Australia) assay in immunocompetent adults with $\mathrm{TB}$, but with no underlying disease.

\section{Biomed Central}




\section{Methods}

\section{Participants and data collection}

All soldiers who were diagnosed with active TB between May 2008 and September 2009 at the Armed Forces Capital Hospital, a central referral military hospital in South Korea, were eligible for this study. Those who could not be followed for at least 6 months or who received anti-TB medication before admission to our hospital were excluded. After giving informed consent, each participant completed a questionnaire regarding their demographics, history of TB, smoking status, and other factors. We performed QFT-GIT assay for each participant before treatment (baseline) and after 1, 3, and 6 months of anti-TB treatment. This study was reviewed and approved by the Institutional Review Board of the Armed Forces Medical Command.

\section{Diagnosis and treatment of TB}

Active pulmonary TB was diagnosed when (1) the patient's sputum was positive for acid-fast staining, or Mycobacterium tuberculosis was cultured; or (2) the patient's data met the definition of a clinical case of TB according to the World Health Organization criteria [11]. To diagnose clinical TB, respiratory symptoms and radiographic lesions on high-resolution computed tomography (HRCT) that were compatible with active TB were mandatory. Active pulmonary TB was defined as the presence of cavities, branching linear opacities, or multiple noncalcified nodules on HRCT [12-14]. For participants with lesions that suggested active TB, but who did not have positive acid-fast smears or $M$. tuberculosis cultures, broad-spectrum antibiotics (a combination of a thirdgeneration cephalosporin and a macrolide) were prescribed for 1 week; if the lesions on chest X-ray or HRCT showed a definite improvement, a diagnosis of active TB was excluded.

TB pleuritis was diagnosed when (1) M. tuberculosis was detected in a culture of pleural fluid or tissue; or (2) positive real-time polymerase chain reaction for M. tuberculosis in pleural fluid or tissue; or (3) an exudative pleural effusion showed lymphocyte predominance, negative cytology, low carcinoembryonic antigen $(<5 \mathrm{ng} / \mathrm{ml})$, and high adenosine deaminase $(\geq 50 \mathrm{IU} / \mathrm{L})$.

TB lymphadenitis was diagnosed when one of the following criteria was met: (1) cultivation of $M$. tuberculosis from lymph node tissue; (2) presence of a caseating granuloma with or without visible acid-fast bacilli; or (3) positive real-time polymerase chain reaction for $M$. tuberculosis in lymph node tissue.

All patients were given standardized anti-TB medication consisting of daily isoniazid (INH), rifampicin (RMP), ethambutol (EMB), and pyrazinamide (PZA) for 2 months, followed by daily INH, RMP, and EMB for
4 months [15]. In cases with INH resistance, daily RMP, EMB, PZA, and a fluoroquinolone (levofloxacin or moxifloxacin) were given for at least 6 months.

\section{Tuberculin skin test}

After the initial blood sampling for the QFT-GIT assay, a TST was performed by trained personnel following standard procedures. For this test, $0.1 \mathrm{ml}(2 \mathrm{TU})$ of purified protein derivate (RT23, Statens Serum Institute, Copenhagen, Denmark) was injected intradermally into the inner side of the left forearm. The transverse induration at the TST site was measured in millimeters after 48-72 h, by one of three experienced nurses. We defined a positive test as one in which there was induration $\geq 10 \mathrm{~mm}$ [16].

\section{Interferon-gamma release assay}

The QFT-GIT was performed according to the manufacturer's instructions. Blood was collected in three special tubes: one coated with the Mycobacterium-tuberculosisspecific peptides ESAT-6, CFP-10, and TB 7.7 (Rv2654, only peptide 4 ); one coated with mitogen, as a positive control; and one without antigen coating, as a negative control. Within $8 \mathrm{~h}$ of blood sampling, the tubes were incubated for $24 \mathrm{~h}$ at $37^{\circ} \mathrm{C}$, centrifuged, and stored in the cold until testing, as specified by the manufacturer. The plasma IFN- $\gamma$ concentration was measured using a commercial QFT-GIT ELISA and was determined as negative, intermediate, or positive (cut-off at $0.35 \mathrm{IU} / \mathrm{ml}$ ) by the manufacturer's software. QFT-GIT reversion to negativity was defined as a change in the IFN $-\gamma$ level from a positive $(\geq 0.35 \mathrm{IU} / \mathrm{ml})$ to a negative result $(<0.35 \mathrm{IU} /$ $\mathrm{ml})$. Because the QFT-GIT ELISA cannot measure IFN- $\gamma$ values $>10 \mathrm{IU} / \mathrm{ml}[7]$ accurately, values $>10 \mathrm{IU} / \mathrm{ml}$ were treated as $10 \mathrm{IU} / \mathrm{ml}$.

\section{Statistical analysis}

Agreement between the TST and QFT-GIT results was measured using the kappa statistic. McNemar's test was used to compare paired proportions of QFT-GIT-positive results. Repeated measures analysis of variance was used to compare the IFN- $\gamma$ levels at different time points, and the results were validated using Mauchly's test of sphericity (equal variance of the differences between levels of the repeated measures factor). The means of different groups were compared using Student's $t$-test. The relationship between clinical characteristics and QFT-GIT reversion to negativity was evaluated using the $\chi^{2}$ test. Statistical significance was assessed at a two-tailed $P$ value of 0.05 , and all data are presented as the mean \pm standard deviation except figure 3. All statistical analyses were conducted using PASW 17.0 (SPSS, Chicago, IL, USA). 


\section{Results}

Demographic and clinical characteristics of the participants

Sixty-seven soldiers with active TB were eligible for this study; eight were lost to follow-up. Thus, 59 (87.9\%) participants completed the study protocol and were included in the final analysis. All participants were male and had a median age of 21 years (range, 20-48). Every participant was negative for human immunodeficiency virus (HIV) and had no other underlying disease (e.g. uncontrolled asthma, diabetes mellitus, and chronic renal failure). Forty-six (78.0\%) patients had pulmonary TB: $13(28.9 \%)$ had positive acid-fast staining of their sputum, and 33 (71.7\%) had M. tuberculosis cultured from their sputum. In 29 of these 33 participants, the isolates were sensitive to all anti-TB medications; the isolates from four patients showed INH mono-resistance. Patients with other types of TB included 11 with pleural TB (including one patient with culture-positive pleural fluid), one with TB lymphadenitis, and one with a TB abscess in the inguinal area (Table 1). All 11 patients with pleural TB and the one patient with a TB abscess had pulmonary parenchymal involvement[17]. All patients in the study had radiologic and clinical improvements, with negative conversion in a sputum exam at 2 months after anti-TB treatment. None of the 59 patients had a relapse of active TB during the followup period of $102 \pm 105$ days (range, 0-433).

\section{Changes in QFT-GIT during anti-TB treatment}

Fifty-seven (96.6\%) patients had positive QFT-GIT results and $56(94.9 \%)$ had positive TST results at the diagnosis of TB. The agreement between the two tests was substantial (kappa $=0.79, P<0.001$ ) [18], with an agreement rate of $98.3 \%$. After treatment, $53(89.8 \%)$ had a positive QFT-GIT result at 1 month; 42 (71.2\%),

Table 1 Demographic and clinical characteristics of the participants included in the final analysis

\begin{tabular}{ll}
\hline Characteristics & Values $(\mathbf{n}=\mathbf{5 9})$ \\
\hline Median age: years (range) & $21(20-48)$ \\
Male: $n$ (\%) & $59(100)$ \\
BCG scar present: $n$ (\%) & $44(74.6)$ \\
Current smoker & $26(44.1)$ \\
Diagnosis & $46(78.0)$ \\
$\quad$ Pulmonary TB (\%) & $13(28.9)^{*}$ \\
$\quad$ Smear positive & $33(71.7)^{*}$ \\
$\quad$ Culture positive & $11(18.6)$ \\
TB pleuritis & $1(1.7)$ \\
TB lymphadenitis & $1(1.7)$ \\
TB abscess & \\
\hline
\end{tabular}

* The percentages were calculated using participants with pulmonary TB as the denominator. at 3 months; and $39(66.1 \%)$, at 6 months. The proportion of patients with a positive QFT-GIT result decreased significantly at 3 months $(P<0.001$; Figure 1$)$.

The IFN- $\gamma$ level at baseline was $4.38 \pm 3.59 \mathrm{IU} / \mathrm{ml}$, and the levels at 1,3 , and 6 months were $3.51 \pm 3.23 \mathrm{IU} / \mathrm{ml}$, $1.80 \pm 2.07 \mathrm{IU} / \mathrm{ml}$, and $1.41 \pm 1.88 \mathrm{IU} / \mathrm{ml}$, respectively. The IFN- $\gamma$ level decreased with time, with a significant decrease at 3 months $(P<0.001)$, but not at 1 month $(P=0.16)$. The IFN- $\gamma$ level did not differ significantly between 3 and 6 months $(P=0.25$, Figure 2$)$. The IFN- $\gamma$ level decreased during treatment in 55 (93.2\%) participants. The mean difference in the IFN- $\gamma$ level between baseline and 6 months was $-3.75 \pm 4.60 \mathrm{IU} / \mathrm{ml}$, and the ratio of the IFN- $\gamma$ level at 6 months to that at baseline was $0.41 \pm 0.58$. The IFN- $\gamma$ level at 6 months was less than half of the baseline level in 43 (72.9\%) participants (Table 2). Throughout the treatment, the IFN- $\gamma$ levels had been lower among TB patients with pleural effusion than among patients without pleural effusion. (Figure 3)

\section{Participants with unusual change of IFN- $\gamma$ response}

Three participants showed increased IFN- $\gamma$ levels after treatment, with levels increasing from 1.89 to $2.02,0.42$ to 1.49 , and 0.98 to $2.19 \mathrm{IU} / \mathrm{ml}$, respectively. In one participant, the IFN- $\gamma$ level remained at $1.87 \mathrm{IU} / \mathrm{ml}$. Two patients with an initial negative QFT-GIT result remained persistently QFT-GIT negative for 6 months (Figure 2).

One subjects with TB lymphadenitis had an IFN- $\gamma$ level of $>10.0 \mathrm{IU} / \mathrm{ml}$ persistently during 6 months of treatment and he was the only participant whose IFN- $\gamma$ level exceeded $10 \mathrm{IU} / \mathrm{ml}$ after completing therapy. His neck lymph node had a longest diameter of $4 \mathrm{~cm}$ at baseline, but was undetectable at treatment completion, and there was no evidence of relapse for 6 months after treatment completion.

\section{Characteristics associated with negative conversion of the QFT-GIT}

C-reactive protein (CRP) level higher than $3 \mathrm{mg} / \mathrm{ml}(P=$ 0.046) and body temperature above $38.3^{\circ} \mathrm{C}(P=0.056)$ at diagnosis were associated with reversion to negativity of the QFT-GIT, as was a lower baseline IFN- $\gamma$ level $(P=0.03$, Table 3$)$.

\section{Discussion}

This study reports the changes over time in the IFN- $\gamma$ levels of young active TB patients with no underlying disease, during treatment with anti-TB medication. All 59 patients were cured; however, only 18 (32.1\%) of the 56 participants with an initial positive QFT-GIT result showed reversion to negativity after 6 months of antiTB medication. With 6 months of treatment, the IFN- $\gamma$ level decreased to less than half of the baseline level in 43 (72.9\%) participants. 


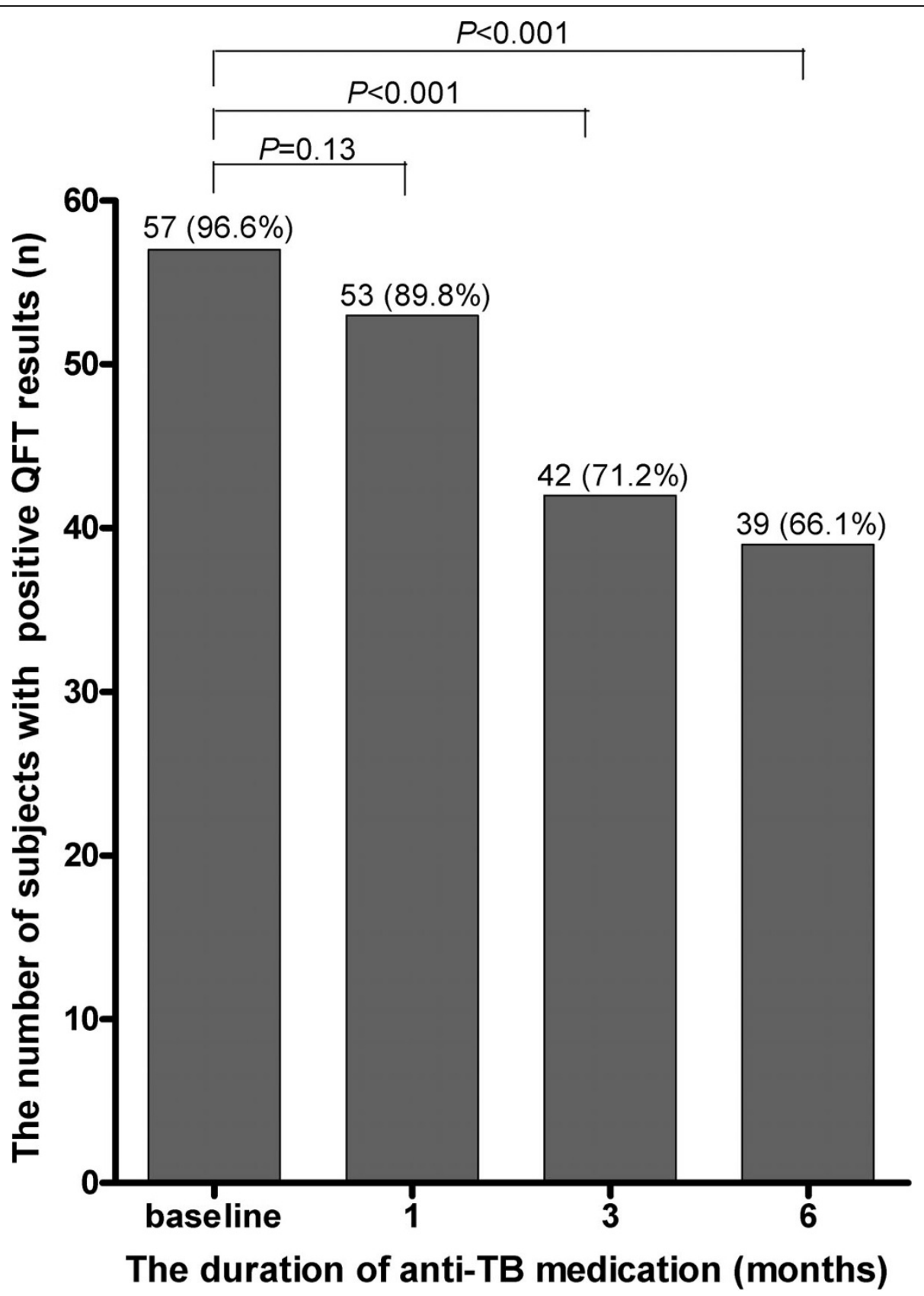

Figure 1 The proportion of active tuberculosis patients with positive QFT-GIT results.

A preliminary report suggested that the IGRA was useful for monitoring the efficacy of anti-TB therapy in patients with active TB [19]. However, subsequent studies reported discrepant results [3]. Longitudinal studies using a QuantiFERON-TB Gold (QFT-G) assay gave variable results. Two studies conducted in Japan showed a progressive decrease of the IFN- $\gamma$ response after anti-TB treatment, with smaller percentages of subjects with positive QFT-G results over time $[20,21]$. By contrast, a study conducted in India showed a persistent IFN- $\gamma$ response during treatment, with positive QFT-G rates of 73\% at baseline and $79 \%$ at 6 months, although the average IFN- $\gamma$ level declined slightly [7]. This discrepancy may be related to the initial IFN- $\gamma$ levels and the burden of TB in the countries. The baseline IFN- $\gamma$ level in the study conducted in India was $4.09 \pm 4.14 \mathrm{IU} / \mathrm{ml}$, which was greater than those in the two studies from Japan $(0.51 \pm 0.15$ and $0.75 \pm 0.15$ $\mathrm{IU} / \mathrm{ml}$ ), and a higher IFN- $\gamma$ level was reported to be associated with a lower likelihood of converting to a negative culture [10]. Furthermore, in high-burden countries, 

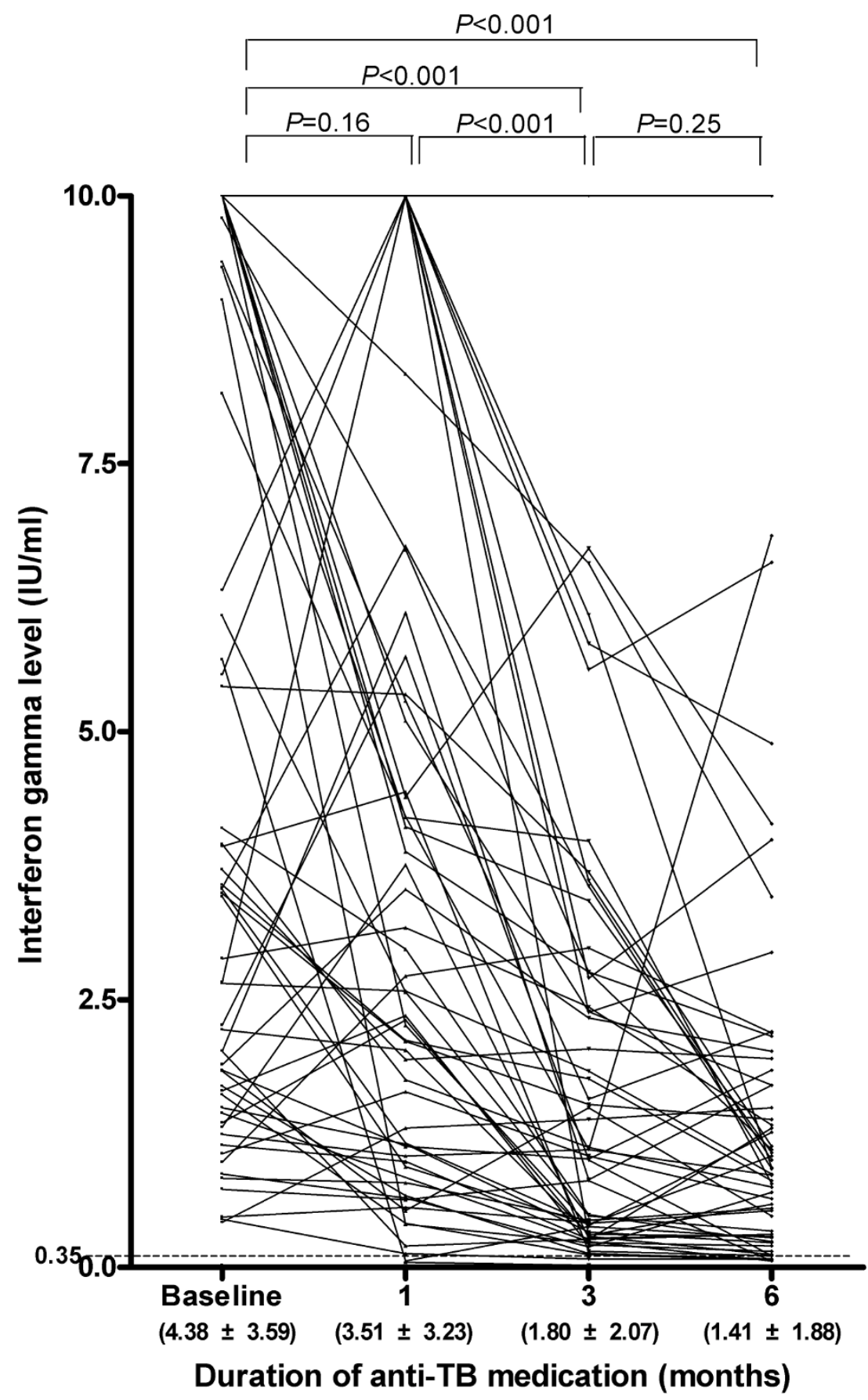

Figure 2 The change in the IFN- $\gamma$ level during successful anti-TB treatment.

ongoing exposure and exogenous re-infection can keep $\mathrm{T}$-cell responses strong, even after the antigen load has declined with therapy.

The lower reversion rate after completing anti-TB treatment $(31.6 \%)$ in our study could be explained by the fact that the initial IFN- $\gamma$ level $(4.38 \pm 3.59 \mathrm{IU} / \mathrm{ml})$ was higher than those in the previous studies in Japan. The higher initial IFN- $\gamma$ level in our study may be associated with the demographic characteristics of the participants, who were young, immunocompetent patients with no underlying disease. To achieve reversion to negativity in patients with a high initial IFN- $\gamma$ level, the absolute decrease must be profound.

In addition to low baseline IFN- $\gamma$ level, higher CRP level and the presence of fever were also associated with the reversion to negativity of QFT-GIT in this study. 
Table 2 Difference and proportion of IFN- $\gamma$ levels at 6 months compared with those at baseline

\begin{tabular}{cl}
\hline Interferon-gamma level & Number of participants (\%/cumulative \%) \\
\hline Difference between baseline and 6 months (IU/ml) \\
$\leq-8$ & $7(11.9 / 11.9)$ \\
$>-8$ and $\leq-5$ & $9(15.3 / 27.1)$ \\
$>-5$ and $\leq-2$ & $11(18.6 / 45.8)$ \\
$>-2$ and $\leq-1$ & $14(23.7 / 69.5)$ \\
$>-1$ and $\leq 0$ & $15(25.4 / 94.9)$ \\
$>0$ and $<1.3$ & $3(5.1 / 100.0)$ \\
\hline Proportion of participants with defined change (\%) \\
$\leq 10$ & $15(25.4 / 25.4)$ \\
$>10$ and $\leq 25$ & $14(23.7 / 49.2)$ \\
$>25$ and $\leq 50$ & $13(22.0 / 71.2)$ \\
$>50$ and $\leq 100$ & $14(23.7 / 94.9)$ \\
$>100$ and $\leq 360$ & $3(5.1 / 100.0)$ \\
\hline
\end{tabular}

The marginal statistical significance $(P=0.056)$ of the association between fever and reversion to negativity may be due to the small number of participants. IL-12dependent IFN- $\gamma$ release is crucial for controlling TB infection [22,23]. Therefore, relatively weak immune responses with lower IFN- $\gamma$ release may be related to a severe initial infectious state, presenting as fever and a high CRP level. Reversion to negativity of the QFT-GIT in these patients may be achieved easily because of the lower initial IFN- $\gamma$ level.
Interestingly, TB patients with pleural effusion had consistently lower IFN - $\gamma$ levels than those without pleural effusion throughout the treatment period. Considering the fact that the development of tuberculous pleural effusion is suggested to be based on delayed type hypersensitivity reaction $[24,25]$, lower IFN- $\gamma$ levels among TB patients with effusion was somewhat unexpected. This observation should be confirmed in future studies involving larger number of patients.

In this study, $96.6 \%$ of the participants with active $\mathrm{TB}$ had positive results on the first QFT-GIT; this rate is higher than previously reported rates. With the exception of two studies from South Korea [26] and Japan [20], most studies reported low sensitivity (64-76\%) with this assay [27-31]. The higher sensitivity of the assay in our study could be explained by the characteristics of the participants, who were mostly young, otherwise healthy, immunocompetent military personnel. The sensitivity of the IGRA is known to decrease significantly with older age [32], HIV infection [33], and chronic renal failure [34].

\section{Conclusion}

Although the IFN- $\gamma$ levels in the QFT-GIT decreased after successful anti-TB treatment in most participants, less than half of them had reversion to negativity of QFT-GIT among young immunocompetent patients with active TB. The reversion of the QFT-GIT with anti-TB medication was more common among patients

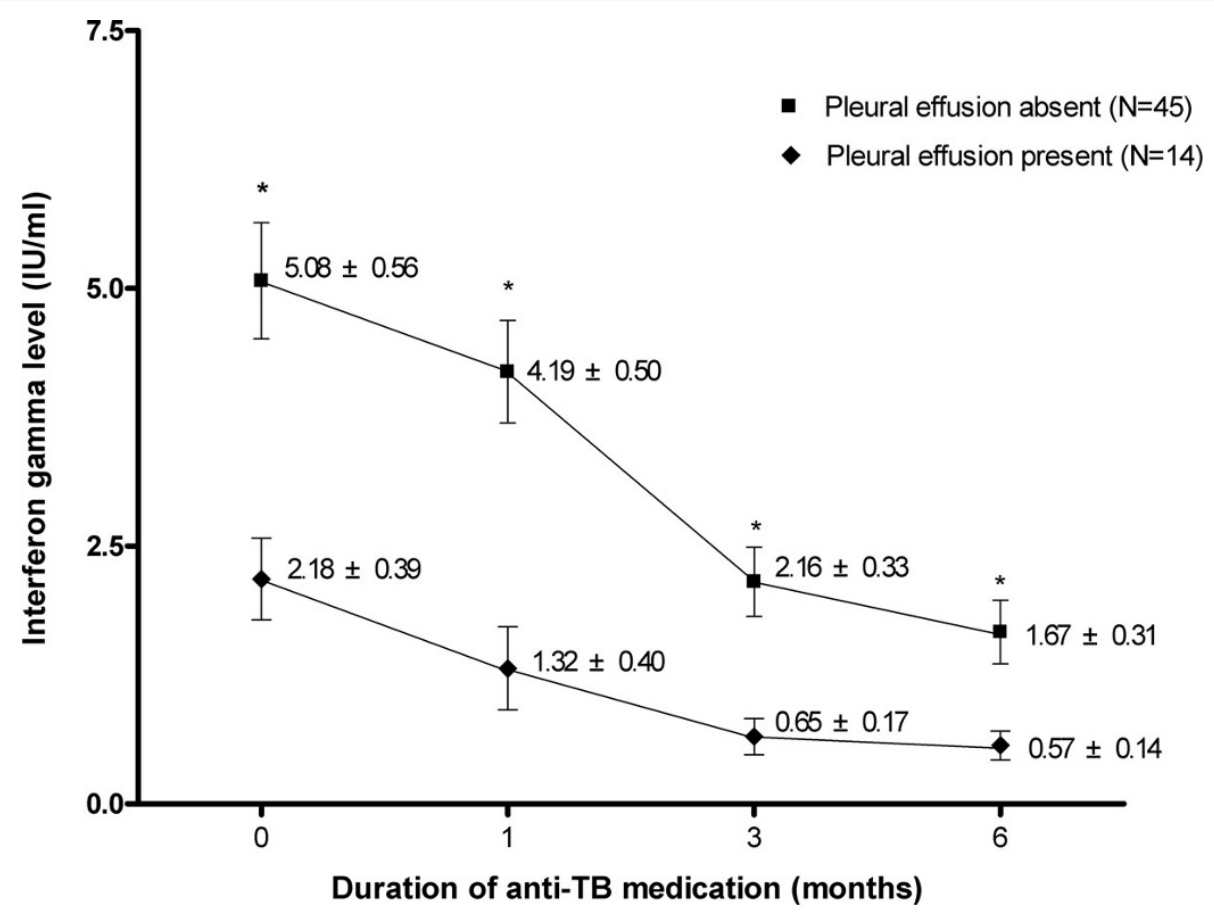

Figure 3 Comparison of changes in the IFN- $\gamma$ level between patients with pulmonary tuberculosis according to the presence of pleural effusion. Data were presented as mean \pm standard error. ${ }^{*} \mathrm{P}<0.01$ (between two groups) 
Table 3 Variables associated with QFT-GIT reversion

\begin{tabular}{|c|c|c|c|c|}
\hline & Number (\%) & Number with reversion (\%) & Odds ratio $(95 \% \mathrm{Cl})$ & $P$ value \\
\hline \multicolumn{5}{|l|}{ Cavity } \\
\hline Present & $18(31.6)$ & $6(33.3)$ & 1.00 (reference) & 0.85 \\
\hline Absent & $39(68.4)$ & $12(30.8)$ & $1.13(0.34-3.71)$ & \\
\hline \multicolumn{5}{|l|}{ Lesion extent } \\
\hline$>$ one lobe & $28(49.1)$ & $8(27.6)$ & 1.00 (reference) & 0.45 \\
\hline one lobe & $29(50.9)$ & $10(35.7)$ & $1.55(0.50-4.77)$ & \\
\hline \multicolumn{5}{|l|}{ Pleural effusion } \\
\hline Absent & $43(75.4)$ & $11(25.6)$ & 1.00 (reference) & 0.10 \\
\hline Present & $14(24.6)$ & $7(50.0)$ & $2.91(0.83-10.17)$ & \\
\hline \multicolumn{5}{|l|}{ CRP } \\
\hline$<3 \mathrm{mg} / \mathrm{dl}$ & $41(73.3)$ & $10(24.4)$ & 1.00 (reference) & 0.046 \\
\hline$\geq 3 \mathrm{mg} / \mathrm{dl}$ & $15(26.8)$ & $8(53.3)$ & $3.54(1.03-12.24)$ & \\
\hline \multicolumn{5}{|l|}{ Body temperature* } \\
\hline$<38.3^{\circ} \mathrm{C}$ & $44(76.8)$ & $11(25.6)$ & 1.00 (reference) & 0.056 \\
\hline$\geq 38.3^{\circ} \mathrm{C}$ & $13(23.2)$ & $7(53.8)$ & $3.50(0.97-12.67)$ & \\
\hline \multicolumn{5}{|l|}{ Baseline QFT-GIT } \\
\hline decrease by $1 \mathrm{IU} / \mathrm{ml}$ & $57(100)$ & $18(31.6)$ & $1.24(1.03-1.49)$ & 0.03 \\
\hline
\end{tabular}

All analysis was performed with exclusion of two participants with initial negative QFT.

*Peak body temperature within 24 hours of initial hospital visit.

QFT-GIT, QuantiFERON-TB gold in-tube assay; CRP, C-reactive protein.

with a lower initial IFN- $\gamma$ level, higher CRP, and fever at the diagnosis of active TB.

\section{Acknowledgements}

This study was supported by the military medical association grant from the Defense Ministry of South Korea. We thank Ho Sik Shin (Department of Internal Medicine, Armed Forces Yangju Hospital) for his assistance in designing the study.

\section{Author details}

${ }^{1}$ Department of Internal Medicine, Armed Forces Capital Hospital, Seongnam, Republic of Korea. ${ }^{2}$ Department of Internal Medicine, Seoul National University Bundang Hospital, Seongnam, Republic of Korea. ${ }^{3}$ Division of Pulmonary and Critical Care Medicine, Department of Internal Medicine and Lung Institute, Seoul National University College of Medicine, Seoul, Republic of Korea.

\section{Authors' contributions}

SWL and JJY planned this study, collected and analyzed the data, and wrote the manuscript. CTL supervised this study. All authors read and approved the final manuscript.

\section{Competing interests}

The authors declare that they have no competing interests.

Received: 28 May 2010 Accepted: 16 October 2010 Published: 16 October 2010

\section{References}

1. Global tuberculosis control: surveillance, planning, financing. WHO report 2007. Geneva: World Health Organization.

2. Foulds J, O'Brien R: New tools for the diagnosis of tuberculosis: the perspective of developing countries. Int J Tuberc Lung Dis 1998, 2(10):778-783.

3. Menzies D, Pai M, Comstock G: Meta-analysis: new tests for the diagnosis of latent tuberculosis infection: areas of uncertainty and recommendations for research. Ann Intern Med 2007, 146(5):340-354.
4. Kang YA, Lee HW, Yoon HI, Cho B, Han SK, Shim YS, Yim JJ: Discrepancy between the tuberculin skin test and the whole-blood interferon gamma assay for the diagnosis of latent tuberculosis infection in an intermediate tuberculosis-burden country. JAMA 2005, 293(22):2756-2761.

5. Mazurek GH, Jereb J, Lobue P, lademarco MF, Metchock B, Vernon A: Guidelines for using the QuantiFERON-TB Gold test for detecting Mycobacterium tuberculosis infection, United States. MMWR Recomm Rep 2005, 54(RR-15):49-55.

6. Dheda K, Pooran A, Pai M, Miller RF, Lesley K, Booth HL, Scott GM, Akbar AN, Zumla A, Rook GA: Interpretation of Mycobacterium tuberculosis antigen-specific IFN-gamma release assays (T-SPOT.TB) and factors that may modulate test results. J Infect 2007, 55(2):169-173.

7. Pai M, Joshi R, Bandyopadhyay M, Narang P, Dogra S, Taksande B, Kalantri S: Sensitivity of a whole-blood interferon-gamma assay among patients with pulmonary tuberculosis and variations in T-cell responses during anti-tuberculosis treatment. Infection 2007, 35(2):98-103.

8. Aiken AM, Hill PC, Fox A, McAdam KP, Jackson-Sillah D, Lugos MD, Donkor SA, Adegbola RA, Brookes RH: Reversion of the ELISPOT test after treatment in Gambian tuberculosis cases. BMC Infect Dis 2006, 6:66.

9. Kobashi Y, Mouri K, Yagi S, Obase Y, Miyashita N, Oka M: Transitional changes in T-cell responses to Mycobacterium tuberculosis-specific antigens during treatment. J Infect 2009, 58(3):197-204.

10. Katiyar SK, Sampath A, Bihari S, Mamtani M, Kulkarni H: Use of the QuantiFERON-TB Gold In-Tube test to monitor treatment efficacy in active pulmonary tuberculosis. Int J Tuberc Lung Dis 2008, 12(10):1146-1152.

11. WHO: Treatment of tuberculosis: guidelines for national programmes., 3 2003.

12. Im JG, Itoh H, Lee KS, Han MC: CT-pathology correlation of pulmonary tuberculosis. Crit Rev Diagn Imaging 1995, 36(3):227-285.

13. Im JG, Itoh H, Shim YS, Lee JH, Ahn J, Han MC, Noma S: Pulmonary tuberculosis: CT findings-early active disease and sequential change with antituberculous therapy. Radiology 1993, 186(3):653-660.

14. Im JG, Webb WR, Han MC, Park JH: Apical opacity associated with pulmonary tuberculosis: high-resolution CT findings. Radiology 1991, 178(3):727-731.

15. Seung KJ, Bai GH, Kim SJ, Lew WJ, Park SK, Kim JY: The treatment of tuberculosis in South Korea. Int J Tuberc Lung Dis 2003, 7(10):912-919. 
16. Targeted tuberculin testing and treatment of latent tuberculosis infection. This official statement of the American Thoracic Society was adopted by the ATS Board of Directors, July 1999. This is a Joint Statement of the American Thoracic Society (ATS) and the Centers for Disease Control and Prevention (CDC). This statement was endorsed by the Council of the Infectious Diseases Society of America. (IDSA), September 1999, and the sections of this statement. Am J Respir Crit Care Med 2000, 161(4 Pt 2):S221-247.

17. Kim HJ, Lee HJ, Kwon SY, Yoon HI, Chung HS, Lee CT, Han SK, Shim YS, Yim JJ: The prevalence of pulmonary parenchymal tuberculosis in patients with tuberculous pleuritis. Chest 2006, 129(5):1253-1258

18. Landis JR, Koch GG: The measurement of observer agreement for categorical data. Biometrics 1977, 33(1):159-174.

19. Carrara S, Vincenti D, Petrosillo N, Amicosante M, Girardi E, Goletti D: Use of a T cell-based assay for monitoring efficacy of antituberculosis therapy. Clin Infect Dis 2004, 38(5):754-756.

20. Kobashi Y, Obase Y, Fukuda M, Yoshida K, Miyashita N, Oka M: Clinical reevaluation of the QuantiFERON TB-2G test as a diagnostic method for differentiating active tuberculosis from nontuberculous mycobacteriosis. Clin Infect Dis 2006, 43(12):1540-1546.

21. Kobashi $Y$, Sugiu T, Ohue Y, Mouri K, Obase Y, Miyashita N, Oka M: Longterm follow-up of the QuantiFERON TB-2G test for active tuberculosis disease. Intern Med 2008, 47(22):1957-1961.

22. Cooper AM, Dalton DK, Stewart TA, Griffin JP, Russell DG, Orme IM: Disseminated tuberculosis in interferon gamma gene-disrupted mice. $J$ Exp Med 1993, 178(6):2243-2247.

23. Flynn JL, Chan J, Triebold KJ, Dalton DK, Stewart TA, Bloom BR: An essential role for interferon gamma in resistance to Mycobacterium tuberculosis infection. J Exp Med 1993, 178(6):2249-2254

24. Apicella MA, Allen JC: A physiologic differentiation between delayed and immediate hypersensitivity. J Clin Invest 1969, 48(2):250-259.

25. Leckie WJ, Tothill P: Albumin turnover in pleural effusions. Clin Sci 1965, 29(2):339-352.

26. Kang YA, Lee HW, Hwang SS, Um SW, Han SK, Shim YS, Yim JJ: Usefulness of whole-blood interferon-gamma assay and interferon-gamma enzymelinked immunospot assay in the diagnosis of active pulmonary tuberculosis. Chest 2007, 132(3):959-965.

27. Dewan PK, Grinsdale J, Kawamura LM: Low sensitivity of a whole-blood interferon-gamma release assay for detection of active tuberculosis. Clin Infect Dis 2007, 44(1):69-73.

28. Goletti D, Carrara S, Vincenti D, Saltini C, Rizzi EB, Schinina V, Ippolito G, Amicosante M, Girardi E: Accuracy of an immune diagnostic assay based on RD1 selected epitopes for active tuberculosis in a clinical setting: a pilot study. Clin Microbiol Infect 2006, 12(6):544-550.

29. Lee JY, Choi HJ, Park IN, Hong SB, Oh YM, Lim CM, Lee SD, Koh Y, Kim WS, Kim DS, et al: Comparison of two commercial interferon-gamma assays for diagnosing Mycobacterium tuberculosis infection. Eur Respir J 2006, 28(1):24-30

30. Nishimura T, Hasegawa N, Mori M, Takebayashi T, Harada N, Higuchi K, Tasaka S, Ishizaka A: Accuracy of an interferon-gamma release assay to detect active pulmonary and extra-pulmonary tuberculosis. Int I Tuberc Lung Dis 2008, 12(3):269-274.

31. Vincenti D, Carrara S, Butera O, Bizzoni F, Casetti R, Girardi E, Goletti D: Response to region of difference 1 (RD1) epitopes in human immunodeficiency virus (HIV)-infected individuals enrolled with suspected active tuberculosis: a pilot study. Clin Exp Immunol 2007, 150(1):91-98.

32. Kobashi Y, Mouri K, Yagi S, Obase Y, Miyashita N, Okimoto N, Matsushima T, Kageoka T, Oka M: Clinical utility of the QuantiFERON TB-2G test for elderly patients with active tuberculosis. Chest 2008, 133(5):1196-1202.

33. Raby E, Moyo M, Devendra A, Banda J, De Haas P, Ayles H, GodfreyFaussett P: The effects of HIV on the sensitivity of a whole blood IFNgamma release assay in Zambian adults with active tuberculosis. PLoS One 2008, 3(6):e2489.

34. Lee SS, Chou K, Su IJ, Chen YS, Fang HC, Huang TS, Tsai HC, Wann SR, Lin HH, Liu YC: High prevalence of latent tuberculosis infection in patients in end-stage renal disease on hemodialysis: Comparison of QuantiFERON-TB GOLD, ELISPOT, and tuberculin skin test. Infection 2009, 37(2):96-102.

\section{Pre-publication history}

The pre-publication history for this paper can be accessed here: http://www.biomedcentral.com/1471-2334/10/300/prepub

doi:10.1186/1471-2334-10-300

Cite this article as: Lee et al: Serial interferon-gamma release assays during treatment of active tuberculosis in young adults. BMC Infectious Diseases 2010 10:300.

\section{Submit your next manuscript to BioMed Central and take full advantage of:}

- Convenient online submission

- Thorough peer review

- No space constraints or color figure charges

- Immediate publication on acceptance

- Inclusion in PubMed, CAS, Scopus and Google Scholar

- Research which is freely available for redistribution

Submit your manuscript at www.biomedcentral.com/submit 